\section{Use of hemoglobin A1C to detect Haitian-Americans with undiagnosed Type 2 diabetes}

\author{
Utilização de hemoglobina A1C no rastreamento de haitianos \\ americanos com diabetes tipo 2 não diagnosticado
}

Joel C. Exebio', Gustavo G. Zarini' , Joan A. Vaccaro', Cristobal Exebio², Fatma G. Huffman'

\begin{abstract}
Objective: To evaluate the validity of hemoglobin $\mathrm{A} 1 \mathrm{C}(\mathrm{A} 1 \mathrm{C})$ as a diagnostic tool for type 2 diabetes and to determine the most appropriate $\mathrm{A} 1 \mathrm{C}$ cutoff point for diagnosis in a sample of Haitian-Americans. Subjects and methods: Subjects $(n=128)$ were recruited from Miami-Dade and Broward counties, FL. Receiver operating characteristics (ROC) analysis was run in order to measure sensitivity and specificity of $\mathrm{A} 1 \mathrm{C}$ for detecting diabetes at different cutoff points. Results: The area under the ROC curve was 0.86 using fasting plasma glucose $\geq 7.0 \mathrm{mmol} / \mathrm{L}$ as the gold standard. An A1C cutoff point of $6.26 \%$ had sensitivity of $80 \%$ and specificity of $74 \%$, whereas an $\mathrm{A} 1 \mathrm{C}$ cutoff point of $6.50 \%$ (recommended by the American Diabetes Association ADA) had sensitivity of $73 \%$ and specificity of $89 \%$. Conclusions: $A 1 C$ is a reliable alternative to fasting plasma glucose in detecting diabetes in this sample of Haitian-Americans. A cutoff point of $6.26 \%$ was the optimum value to detect type 2 diabetes. Arq Bras Endocrinol Metab. 2012;56(7):449-55
\end{abstract}

\section{Keywords}

Type 2 diabetes; hemoglobin A1C; diagnosis; Haitians

\section{RESUMO}

Objetivo: Avaliar a validade da hemoglobina A1C (A1C) como ferramenta para o diagnóstico de diabetes tipo 2 e determinar o ponto de corte mais apropriado para a A1C no diagnóstico de uma amostra de haitianos americanos. Sujeitos e métodos: Os sujeitos $(n=128)$ foram recrutados dos condados de Miami-Dade e Broward na Flórida. A análise ROC (Receiver operating characteristics) foi feita de forma a medir a sensibilidade e especificidade de A1C para a detecção do diabetes em diferentes pontos de corte. Resultados: $A$ área sob a curva ROC foi 0,86 usando a glicemia de jejum $\geq 7,0 \mathrm{mmol} / \mathrm{L}$ como padrão-ouro. 0 ponto de corte de $6,26 \%$ para a $\mathrm{A} 1 \mathrm{C}$ apresentou sensibilidade de $80 \%$ e especificidade de $74 \%$, enquanto o ponto de corte de $6,50 \%$ (recomendado pela American Diabetes Association - ADA) apresentou uma sensibilidade de $73 \%$ e especificidade de $89 \%$. Conclusões: A A1C foi uma alternativa confiável para a glicemia de jejum na detecção do diabetes nesta amostra de haitianos americanos. Um ponto de corte de 6,26\% foi o valor ótimo para a detecção do diabetes tipo 2. Arq Bras Endocrinol Metab. 2012;56(7):449-55

\section{Descritores}

Diabetes tipo 2; hemoglobina A1C; diagnóstico; haitianos
${ }^{1}$ Florida International University, Department of Dietetics and Nutrition, Miami, FL, United States ${ }^{2}$ Universidad Privada Antenor Orrego, Department of Biostatistics, Trujillo, Peru

\section{INTRODUCTION}

$\mathrm{T}$ raditionally, the diagnosis of diabetes has been based on plasma glucose. Both fasting plasma glucose (FPG) and oral glucose tolerance test (OGTT) have been widely used for more than three decades. However, both tests are inconvenient because they require fasting of at least 8 hours and, in the case of the OGTT, staying in the clinical facility for a long period of time.

In recent years, several studies have examined the validity of hemoglobin $\mathrm{AlC}(\mathrm{AlC})$ as a diagnostic tool for type 2 diabetes (T2D) (1-4). AlC represents a measure of mean blood glucose during the two months 
before the measurement, and does not require fasting or any special preparation. In 2009, an International Expert Committee recommended the use of AlC to diagnose diabetes with a cutoff point of $\geq 6.5 \%$ (5). In 2010, the American Diabetes Association (ADA) adopted this criterion (6). However, it was recognized that AlC levels may vary according to the ethnicity (7).

Data revealed that different ethnic groups show variable sensitivity and specificity for AlC. Variations may be related to genetic differences in hemoglobin concentration, glycation rates, and lifespan and number of red blood cells $(8,9)$. When the recommended AlC cutoff point $(\geq 6.5 \%)$ was tested in a sample representative of the general US population, sensitivity of $\mathrm{AlC}$ was lower compared with FPG. In fact, with this recommended cutoff point, AlC identified 33\% less cases of undiagnosed diabetes than FPG $\geq 7.0 \mathrm{mmol} / \mathrm{L}$ (10). Therefore, an argument for population-specific AlC cutoff points emerged, especially among high risk populations.

Haitians are one of those high risk populations. According to the International Diabetes Federation, the prevalence of T2D in Haiti was $7.2 \%$ for 20 to 79 -year-olds in 2010 (11). Official data for Haitian-Americans (HA) are not available. A small sample (n = 51) collected in a Haitian community (Little Haiti) in the Miami-Dade County, FL, among Haitian immigrants estimated a $33 \%$ prevalence of diabetes (12). Since acculturation may increase obesity rates in Haitian immigrants, prevalence of T2D is likely to be higher among them compared with Haitians living in Haiti. According to the US Census Bureau, there are 548,199 Haitians living in the US, $30 \%$ of whom reside in the Miami-Dade and Broward Counties, FL, making them the second largest immigrant group (behind Cubans) in those counties (13).

The aims of this study were to evaluate the validity of $\mathrm{AlC}$ as a diagnostic tool for $\mathrm{T} 2 \mathrm{D}$, and to determine the most appropriate AlC cutoff point for T2D diagnosis in a sample of HA aged $\geq 35$ years old, using the criteria of FPG $\geq 7.0 \mathrm{mmol} / \mathrm{L}$ as the cutoff point for diabetes diagnosis.

\section{METHODS}

\section{Parent study}

\section{Participants}

Our current study used male and female adults, $\geq 35$ years, who were not diagnosed with diabetes in the pa- rent, case/control study of HA with T2D ( $\mathrm{n}=130)$, and without diabetes $(n=129)$. To be considered a $\mathrm{HA}$, respondents needed to self-report having two parents born in Haiti. The candidates were screened by a trained interviewer, who was familiar with Haitian culture and who spoke English and Creole. Questions concerning length of stay in the United States and place of birth were asked to candidates who qualified. The target population was recruited to achieve sufficient power $(80 \%)$ to determine a medium effect $(\geq 0.50)$ size in cardiovascular disease risk factors and to distinguish differences among 4 groups (gender and two age categories) for cases (with diabetes) and controls (without diabetes).

It was determined that 240 participants ( 30 participants per four groups with diabetes, $\mathrm{n}=120$, and without diabetes, $\mathrm{n}=120$ ) would be sufficient, based on our previous studies in other populations and by using Cohen's rule of thumb ( $\mathrm{n}=30$ per group) (14). Since we anticipated cases of undiagnosed diabetes, the target sample size was increased to accommodate reclassification and possible missing data.

\section{Data collection for the parent study}

Recruitment was conducted by alternating between selecting potential subjects with and then without T2D. Recruitment of HA participants $(\mathrm{n}=259)$ was from community-based sources: (a) Local diabetes educators \& community health practitioners in Miami-Dade and Broward Counties (several local diabetes educators who were either former students or in close contact with the Department of Dietetics and Nutrition at Florida International University-FIU; official letters of invitation outlining the study mailed to the diabetes educators and health professionals in Miami-Dade and Broward county areas requesting their cooperation in recruiting individuals); (b) FIU faculty, staff and students (invitational flyers were distributed to all university faculty, staff and students using the university-wide e-mail system and explaining the research protocol and requesting their assistance in the study); (c) Several residential rental facilities also agreed to help in the recruitment process; (d) Advertisements (printed ads were placed in local Haitian newspapers and principal gathering places of these groups, such as churches, supermarkets, and restaurants; radio advertisement on local Creole stations was also aired).

When the recruitment target was reached $(259$, as explained in the "participants" section), all efforts to 
recruit participants stopped. Interested participants were initially interviewed on the phone. At that moment, the study purpose was explained and the age and gender of the responders were determined. To ascertain T2D status, each participant who self-reported having diabetes was asked for age of diagnosis and initial treatment modalities. Exclusion criteria were belonging to any other ethnicity, age $<35$ years old, pregnant or lactating women. If a subject was determined to be eligible, then his or her participation was requested at the Human Nutrition Laboratory at FIU. Participants were instructed to refrain from smoking, consuming any food or beverages except water, and engaging in any unusual exercise for at least eight hours prior to blood collection.

This study was approved by the Institutional Review Board at FIU. The purpose and protocol of the study were explained to the subjects, and their written consent, either in English or Creole, was obtained before the study began. Laboratory results showed that fifteen participants who reported not having diabetes were reclassified as having T2D according to FPG $\geq$ $7.0 \mathrm{mmol} / \mathrm{L}$. These participants were given their laboratory results and referred to their physicians.

\section{Present study}

For the present study data analysis, subjects who reported previous diagnosis of diabetes $(n=130)$ or were missing values for AlC $(\mathrm{n}=1)$ were excluded. A total of 128 participants were included in the analysis of the data. Subjects who reported previous diagnosis of diabetes were excluded from our analysis because they were taking medication that decreased their FPG below the threshold of diagnosis, which is, in fact, the goal of the diabetes treatment.

\section{Measures}

Twenty $\mathrm{mL}$ of venous blood were collected from each subject after an overnight fast (at least 8 hours) by a certified phlebotomist using standard laboratory techniques. Blood samples were collected in two tubes: a Vaccutainer Serum Separator Tube (SST) for analysis of glucose, and another tube containing ethylenediamine tetra-acetic acid (EDTA) to analyze AlC. After complete coagulation (30-45 minutes), SST was centrifuged at 2,500 RPM for 30 minutes. Serum was transferred from SST into labeled plastic tubes for glucose analysis. Glucose levels were measured by hexokinase enzymatic methods. AlC percentages were measured in whole blood with close tube sampling (CTS), in duplicate $(\mathrm{CV}<1.7 \%)$, with the Roche Tina Quant Second Generation AlC (ACl-2) immunoassay method of Laboratory Corporation of America, Miami, FL (LabCorp $\left.{ }^{\circledR}\right)$. The immunoassay method expresses AlC as a percent of total hemoglobin $(\mathrm{Hb})$; whereas High Pressure Liquid Chromatography (HPLC) expresses AlC as a percent of total HbA. Since amino acids substitution in $\mathrm{HbS}$ and $\mathrm{HbC}$ (the most common variants of $\mathrm{AlC}$ ) are close to the glycated $\mathrm{N}$-terminus, it is possible to overestimate $\mathrm{AlC}$; however, several studies have found comparable results using standard techniques (15-17). The system used for our assays has matched the National Glycohaemoglobin Standardization Program (NGSP) against the $\mathrm{Hb}$ variants and has been certified to follow The Diabetes Control and Complications Trial (DCCT) $(15,16)$. Moreover, our immunoassay method has been validated against boronate-affinity HPLC in two groups of African American patients, one with hemoglobinopathy and another without hemoglobinopathy, and whose $\mathrm{AlC}<7.0 \%$ (17).

\section{Statistical analysis}

Data were divided into three categories according to the current ADA classification (6): normal FPG $(<5.6$ $\mathrm{mmol} / \mathrm{L})$, impaired fasting glucose (IFG) (5.6-6.9 $\mathrm{mmol} / \mathrm{L})$, and undiagnosed diabetes $(\geq 7.0 \mathrm{mmol} / \mathrm{L})$. Percentages of subjects above AlC cutoff points among the three categories were compared using bar graphs. Mean AlC for subjects with normal FPG (< $5.6 \mathrm{mmol} / \mathrm{L}$ ) was computed. Sensitivity and specificity were evaluated at $1,2,3$, and 4 standard deviations above this mean. Also, the cutoff point recommended by the ADA for diabetes diagnosis was plotted in the analysis ( $\mathrm{AlC} \geq 6.5 \%$ ). The ADA criterion for diagnosing diabetes with FPG $\geq 7.0 \mathrm{mmol} / \mathrm{L}$ was considered the gold standard.

Receiver operating characteristics (ROC) analysis was run in order to measure sensitivity and specificity of AlC in detecting diabetes at different cutoff points, and to determine the best predictive cutoff value (18). Sensitivity is the proportion of subjects at or above the AlC cutoff point who have diabetes (FPG $\geq 7.0$ $\mathrm{mmol} / \mathrm{L})$. Specificity is the proportion of individuals with AlC level below the cutoff point who do not have diabetes $(\mathrm{FPG}<7.0 \mathrm{mmol} / \mathrm{L})$. The ROC curve plots sensitivity versus 1 minus specificity at each cutoff level. 
The greater the area under the curve (AUC), the better the prediction value of $\mathrm{AlC}$ for detecting diabetes. An AUC of 0.5 means no prediction value, whereas a value of 1.0 means perfect prediction value. Statistical analysis was run using SPSS 18.0 (Chicago).

\section{RESULTS}

Participants were all born in Haiti and reported migrating to the United States. There was no significant difference in the length of stay (less than 10 years) for those with undiagnosed diabetes compared with those without diabetes $(20.0 \%$ and $30.9 \%$ respectively, $\mathrm{P}=$ 0.550). The linear correlation between AlC and FPG was highly significant $(\mathrm{P}<0.001)$, with a correlation coefficient of 0.75 . Mean AlC for participants with normal FPG, IFG and diabetes were $5.8 \pm 0.46 \%, 6.1$ $\pm 0.47 \%$, and $7.6 \pm 1.75 \%$, respectively $(\mathrm{P}<0.001)$. No significant differences were found for age, gender, body mass index (BMI), and waist circumference among the three categories. These values were $52.5 \pm 10.5$ years, $51 \%$ female, $28.6 \pm 4.6 \mathrm{~kg} / \mathrm{m}^{2}$, and $95.6 \pm 12.1 \mathrm{~cm}$ for normal FPG $(\mathrm{n}=75) ; 57.3 \pm 10.6$ years, $50 \%$ female, $29.3 \pm 5.7 \mathrm{~kg} / \mathrm{m}^{2}$, and $96.8 \pm 14.1 \mathrm{~cm}$ for IFG $(\mathrm{n}=$ $38) ; 53.2 \pm 13.5$ years, $40 \%$ female, $30.1 \pm 5.9 \mathrm{~kg} / \mathrm{m}^{2}$, and $97.9 \pm 11.6 \mathrm{~cm}$ for subjects with T2D $(\mathrm{n}=15)$.

Cutoff points were determined using mean $\mathrm{AlC}$ for participants with normal FPG and adding 1, 2, 3, and 4 standard deviations. These points were $6.26 \%, 6.72 \%$, $7.18 \%$, and $7.64 \%$ respectively. In addition, the cutoff point recommended by the $\mathrm{ADA}(\mathrm{AlC} \geq 6.5 \%)$ was also evaluated. Figure 1 shows the percentage of the population at or above specific cutoff values. Thirty-two percent of the population had AlC levels at or above $6.26 \%$ and $18.8 \%$ had AlC levels at or above $6.50 \%$. A total of $44.7 \%$ of subjects with IFG and $80 \%$ with undiagnosed diabetes were detected with an AlC cutoff point of $6.26 \%$. Similarly, $18.4 \%$ of subjects with IFG and $73.3 \%$ of participants with undiagnosed diabetes were detected with an AlC cutoff point of $6.50 \%$ (recommended by the ADA).

In this specific population, $\mathrm{AlC}$ showed a high predictive value for detecting undiagnosed diabetes. The area under the ROC curve was 0.86 (Figure 2). In addition, an AlC cutoff point of $6.26 \%$ had sensitivity of $80 \%$ and specificity of $74 \%$, whereas an AlC cutoff point of $6.50 \%$ had sensitivity of $73 \%$ and specificity of $89 \%$. Sensitivity decreased as specificity increased with every increasing cutoff value (Table 1 ).

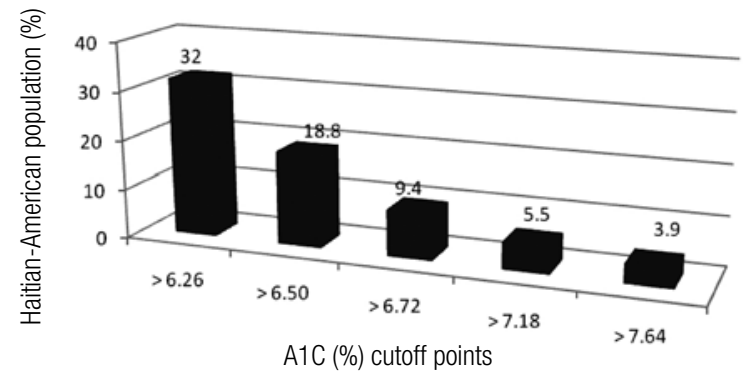

Figure 1. Percentage of Haitian-Americans aged $\geq 35$ years old at different $\mathrm{A} 1 \mathrm{C}$ cutoff points.

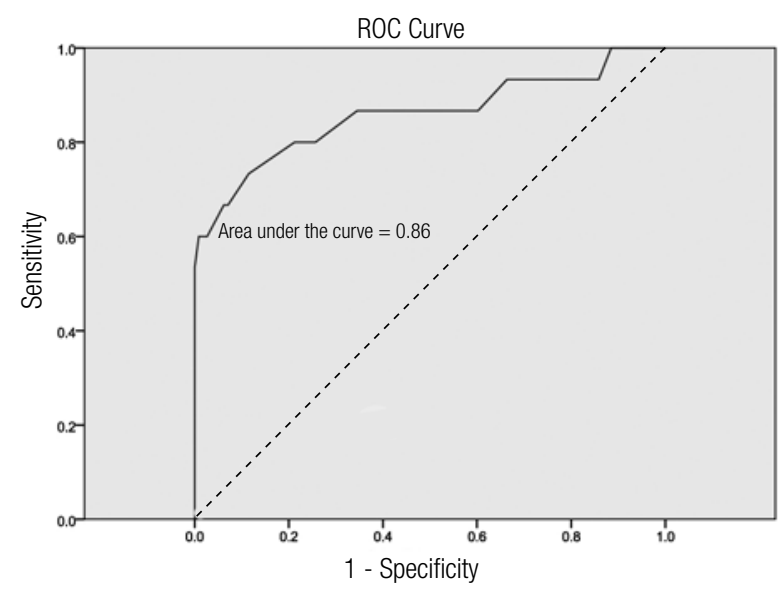

Figure 2. Continuous line: $\mathrm{ROC}$ curve for $\mathrm{A} 1 \mathrm{C}$ as a diagnostic indicator for diabetes (fasting plasma glucose $\geq 7.0 \mathrm{mmol} / \mathrm{L}$ ). Dotted line: Diagonal indicating area under the curve $=0.50$.

Table 1. Sensitivity and specificity of $\mathrm{A} 1 \mathrm{C}$ for detecting undiagnosed diabetes in Haitian-Americans (fasting plasma glucose $\geq 7.0 \mathrm{mmol} / \mathrm{L}$ ) at increasing $\mathrm{A} 1 \mathrm{C}$ cutoff points

\begin{tabular}{lcc}
\hline A1C cutoff (\%) & Sensitivity & Specificity \\
\hline 6.26 & 80 & 74 \\
6.50 & 73 & 89 \\
6.72 & 60 & 97 \\
7.18 & 47 & 100 \\
7.64 & 33 & 100 \\
\hline
\end{tabular}

Data are \%. Sensitivity: $100 \times$ TP/(TP + FN). Specificity: $100 \times$ TN/(TN + FP).

TP: true positive (above the cutoff level for $A 1 C$ and $F P G \geq 7.0 \mathrm{mmol} / \mathrm{L}$ ); $F \mathrm{~N}$ : false negative (below the cutoff level for $\mathrm{A} 1 \mathrm{C}$ and $\mathrm{FPG} \geq 7.0 \mathrm{mmol} / \mathrm{L}$ ); TN: true negative (below the cutoff level for $\mathrm{A} 1 \mathrm{C}$ and $\mathrm{FPG}<7.0 \mathrm{mmol} / \mathrm{L}$ ); $\mathrm{FP}$ : false positive (above the cutoff level for $\mathrm{A} 1 \mathrm{C}$ and $\mathrm{FPG}<$ $7.0 \mathrm{mmol} / \mathrm{L})$.

\section{DISCUSSION}

The ADA has adopted AlC as a valid diagnostic tool for diabetes on the basis that the test is now standardized, does not require fasting, has less intra-individual variability than FPG, and is not affected by stress or illness. 
The recommended cutoff value for diabetes diagnosis has been set at $\mathrm{AlC} \geq 6.5 \%$ (6). In a recent study using data from the National Health and Nutrition Examination Survey (NHANES), AlC $\geq 6.5 \%$ detected only $30 \%$ of the subjects with undiagnosed diabetes. In addition, $19 \%$ of subjects with undiagnosed diabetes were detected by both FPG and OGTT, but not by AlC. Similarly, $1 \%$ of the population previously diagnosed with diabetes, but who has not taken medication yet, was not detected by AlC (10). These results from a sample representative of the national US population demonstrate that the arbitrary cutoff point of $6.5 \%$ should be considered with caution.

Studies from several countries have documented that different ethnicities have different AlC values ( 1 $4,8)$. High sensitivity is important for minorities, even at the expense of lower specificity, in order for cases to be discovered. In the US, the Diabetes Prevention Program has shown that African Americans and Hispanics with impaired glucose tolerance (IGT) had higher AlC values compared with non-Hispanic Whites with IGT, even after adjusting for confounding variables. This finding may be explained by other factors that are not related to glucose control such as hemoglobin glycation rate or red blood cell survival time (9).

In our sample, mean $\mathrm{AlC}$ for subjects with normal FPG $(\mathrm{FPG}<5.6 \mathrm{mmol} / \mathrm{L})$ was $5.8 \% \pm 0.46 \%$, which is higher compared with other populations. For instance, in data obtained from the NHANES III, mean for subjects with normal FPG was $5.17 \% \pm 0.45 \%$ (19). The difference is even greater if we take into consideration that, in this study, normal FPG was defined as FPG < $6.1 \mathrm{mmol} / \mathrm{L}$, which may have increased mean AlC compared with a cutoff of FPG $<5.6 \mathrm{mmol} / \mathrm{L}$. Means for the US population without diabetes are usually higher because they include people with normal and high FPG. However, they are still lower than that found in our sample for subjects with normal FPG. For instance, the overall mean AlC found in the NHANES for non-Hispanic Whites, non-Hispanic Blacks and Mexican Americans without diabetes were $5.3 \pm 0.01,5.4 \pm$ 0.01 , and $5.4 \pm 0.01 \%$, respectively (20). From these results, it is inferred that even in the presence of normal FPG, AlC levels were elevated in our sample of HA compared with the US population without diabetes. Furthermore, 32\% of HA without diabetes had AlC levels greater than $6.26 \%$. In the NHANES, only $2.9 \%$ of the US population without diabetes had AlC greater than $6.1 \%(20)$. Therefore, in this particular sample, there is a considerable proportion of HA with high AlC compared with the general US population without diabetes.

In our sample, AlC showed high predictive value in detecting undiagnosed T2D $(\mathrm{AUC}=0.86)$. However, our optimal cutoff point differs from the one suggested by the ADA. Since the mean for normal subjects $\pm 1 S D$ is considered normal range in any test $(5.8 \pm 0.46 \%$ in our sample), any value that is above the normal range should be considered abnormal ( $>6.26 \%$ for our sample). This is further confirmed by the ROC analysis. Using an AlC cutoff point of $6.26 \%$ (1 SD above the mean for participants with normal FPG) we had $80 \%$ sensitivity and $74 \%$ specificity. Applying the AlC cutoff point of $6.5 \%$ adopted by the ADA, we had $73 \%$ sensitivity and $89 \%$ specificity. The cutoff point recommended by the ADA had lower sensitivity but higher specificity. This issue was addressed by the International Expert Committee who recommended the cutoff point (5). The argument was that specificity is more important than sensitivity because diagnosing subjects as positive when in fact, they are not, will be costly for the health system. While this may be true for the general population, in minorities like HA with a high prevalence of T2D and a high rate of poverty, the cost of complications caused by undiagnosed diabetes may offset the cost related to false positives.

This is further confirmed by studies in different high risk populations around the world that suggest either $\geq 6.1 \%$ or $\geq 6.2 \%$ as the optimum cutoff point for diabetes diagnosis (1-4,21-23) and by the low sensitivity found for AlC when the recommended cutoff point was applied to general US population (10). It should also be noted that $44.7 \%$ of the participants with IFG were detected by the $6.26 \%$ cutoff point, which indicates that a much lower cutoff value should be used for that purpose in this particular sample.

One reason for the lack of consensus for routine diabetes screening may be the lack of diagnostic accuracy of AlC in earlier studies. Now that technology has improved, evidence for $\mathrm{AlC}$ as a diagnostic tool for minorities and hard-to-reach population may be built. Once the barrier of 8 -hour fasting is removed for these groups, early diagnosis and lifestyle management would have the potential to reduce diabetes-related complications. The predictive validity of $\mathrm{AlC}$ as a diagnostic tool (compared with FPG) was found to vary by risk factor score categories (low, moderate, and high prevalence) in a nationally representative sample (24). The 
investigators found that intermediate $\mathrm{AlC}(5.5 \%-6.0 \%)$ could exclude diabetes for persons in the moderate, but not in the high risk groups (24). Since minorities such as HA are at high risk for diabetes, lower AlC cutoffs would increase sensitivity at the expense of lower specificity. The fact that AlC levels indicating high glycemia are positively correlated with microvascular complications (24) offsets the expense of false diagnoses.

The new diagnostic criterion will have important public health implications for high risk populations. According to our data, a considerable proportion of HA in our sample will be missed by the established cutoff point and will be left without treatment. It is imperative to have defined specific cutoff points, to explain why $\mathrm{HA}$ in our sample have high AlC even in the presence of normal FPG, and to examine how the rates of complications are related to AlC levels in this population.

The prevalence of undiagnosed diabetes was $11.7 \%$ (15/128) in this study. Several limitations need to be noted. Our sample may not represent the HA population in Miami-Dade County due to the small sample size and selection bias. HA who were willing to participate in a study that involved revealing social information and drawing blood may have different risk factors compared with those HA who were asked to participate, but refused. Although community leaders generally have access to hard-to-reach HA, they may have selectively approached HA with more cooperative social characteristics. Another limitation of this study was that data was taken in a single time-point. As such, temporal changes in Miami-Dade County were not taken into account.

Technical limitations existed, as well. Although FPG is the gold standard, the ADA recommends that two tests are used for accuracy, and only one measure was taken in this study. Regarding interference of hemoglobin variants, the most common variant for our population would be the $\mathrm{HbC}$ or the $\mathrm{HbS}$ trait, if $\mathrm{HA}$ were sampled in the "Black, non-Hispanic" category (25). The National Diabetes Clearinghouse (NIDC) estimates $8 \%$ of African Americans have the $\mathrm{HbS}$ trait and $2.3 \%$ have the $\mathrm{HbC}$ trait (26). Even though the immunoassay method used to assess $\mathrm{AlC}$ was validated against ion-exchange HPLC, $\mathrm{HbS}$ or $\mathrm{HbC}$ are close to the glycated $\mathrm{N}$-terminus and interference resulting in higher readings cannot be completely ruled out (17). However, interference of the $\mathrm{HbS}$ or $\mathrm{HbC}$ traits are most likely to be found at the extremely high AlC values (17).
Relative contributions of fasting and postprandial hyperglycemia were found to vary across AlC quintiles in a study by Monnier and cols. (27). However, fasting hyperglycemia was critical for AlC values above $8.4 \%$, since postprandial exposure remains stable in the three upper quintiles (27). Three categories were compared in our analysis: normal, IFG, and undiagnosed T2D using FPG. As AlC values were also from fasting blood samples, postprandial glucose levels would not be an issue in the determination of cutoff points.

AlC may be useful in detecting diabetes in community settings among HA. A positive test should be confirmed by fasting plasma glucose or a second AlC reading. However, our study with only one AlC and FPG reading mimics a common decision-making practice for diabetes diagnosis among this particular hard-to-reach population.

In our study, AlC showed a high predictive value for detecting undiagnosed diabetes in HA. A cutoff point of $6.26 \%$ (1 SD above the mean for subjects with normal FPG) was the optimum value to detect undiagnosed T2D in this particular sample. Larger cross-sectional and prospective longitudinal studies are needed to confirm these results.

Acknowledgments: Funding for this research was provided by The National Institute of Health (NIH), National Institute of Diabetes and Digestive and Kidney Diseases (NIDDK), and is supported by grant NIH/MBRS/SCORE AC\# 124401529/42 and NIH/NIDDK AC\# 5SCIDK083060-01.

Disclosure: no potential conflict of interest relevant to this article was reported.

\section{REFERENCES}

1. Colagiuri S, Cameron A, Hussain Z, Shaw J, Zimmet P. Screening for type 2 diabetes and impaired glucose metabolism: the Australian experience. Diabetes Care. 2004;27:367-71.

2. Mannucci E, Ognibene A, Sposato I, Brogi M, Gallori G, Bardini $\mathrm{G}$, et al. Fasting plasma glucose and glycated haemoglobin in the screening of diabetes and impaired glucose tolerance. Acta Diabetol. 2003;40:181-6.

3. Tavintharan S, Chew LSW, Heng DMK. A rationale alternative for the diagnosis of diabetes mellitus in high risk individuals. Ann Acad Med Singapore. 2000;29:213-8.

4. Ko GTC, Chan JCN, Yeung VTF, Chow CC, Tsang LWW, Li JKY, et al. Combined use of a fasting plasma glucose concentration and $\mathrm{HbA1c}$ or fructosamine predicts the likelihood of having diabetes in high-risk subjects. Diabetes Care. 1998;21:1221-5.

5. International Expert Committee: International Expert Committee report on the role of the $\mathrm{A} 1 \mathrm{C}$ assay in the diagnosis of diabetes. Diabetes Care. 2009;32:1327-34.

6. American Diabetes Association: Diagnosis and Classification of Diabetes Mellitus. Diabetes Care. 2010;33(Suppl.1):S62-9. 
7. American Diabetes Association: Standards of Medical Care in Diabetes 2011. Diabetes Care. 2011;34 (Suppl. 1):S11-61.

8. Anand SS, Razak F, Vuksan V, Gerstein HC, Malmberg K, Yi Q, et al. Diagnostic strategies to detect glucose intolerance in a multi-ethnic population. Diabetes Care. 2003;26:290-6.

9. Herman WH, MaY, Uwaifo G, Haffner S, Kahn SE, Horton ES, et al. Differences in $\mathrm{A} 1 \mathrm{C}$ by race and ethnicity among patients with impaired glucose tolerance in the Diabetes Prevention Program. Diabetes Care. 2007;30:2453-7.

10. Cowie CC, Rust KF, Byrd-Holt DD, Gregg EW, Ford ES, Geiss LS, et al. Prevalence of diabetes and high risk for diabetes using hemoglobin A1C criteria in the US population in 1988-2006. Diabetes Care. 2010;33:562-8.

11. Prevalence Estimates of Diabetes Mellitus 2010. International Diabetes Federation, 2000. Available from: http://archive.diabetesatlas.org/content/nac-data. Accessed on: Jan 4, 2012.

12. Rosen A, Sharpe I, Rosen J, Doddard M, Abad M. The prevalence of type 2 diabetes in the Miami-Haitian community. Ethnic Dis. 2007; 17:S3-4.

13. US Census Bureau. Census 2000 Summary File 4. Selected population profile: Haitians. Washington, DC, US Census Bureau, 2000. Available from: http://factfinder2.census.gov. Accessed on: Jan 4, 2012.

14. Cohen J. Statistical power analysis for the behavioral sciences. 2nd ed. Hillsdale, NJ: Erlbaum; 1988.

15. Flemming JK. Evaluation of HbA1c on Roche COBAS Integra 800 closed tube system. Clin Biochem. 2007;40:822-7.

16. National Glycohemoglobin Standardization Program. List of NGSP certified methods. Available from: http://www.ngsp.org/ docs/methods.pdf. Accessed on: May 7, 2012.

17. Abedie JM, Koelsch AA. Performance of the Roche Second Generation Hemoglovin A1c Immunoassay in the presence of $\mathrm{Hb}-\mathrm{S}$ or Hb-CTraits. Ann Clin Lab Sci. 2008;38(1):31-6.

18. Beck JR, Shultz EK. The use of relative operating characteristic (ROC) curves in test performance evaluation. Arch Pathol Lab Med. 1986;110:13-20.
19. Rohlfing CL, Little RR, Wiedmeyer HM, England JD, Madsen R, Harris $\mathrm{Ml}$, et al. Use of $\mathrm{GHb}(\mathrm{HbA} 1 \mathrm{c})$ in screening for undiagnosed diabetes in the US population. Diabetes Care. 2000;23(2):187-91.

20. Selvin $E$, Zhu $H$, Brancati FL. Elevated $A 1 C$ in adults without a history of diabetes in the US. Diabetes Care. 2009;32(5):828-33.

21. Jesudason DR, Dunstan K, Leong D, Wittert GA. Macrovascular risk and diagnostic criteria for type 2 diabetes. Implications for the use of FPG and $\mathrm{HbA} 1 \mathrm{c}$ for cost-effective screening. Diabetes Care. 2003;26:485-90.

22. Herdzik E, Safranow K, Ciechanowski K. Diagnostic value of fasting capillary glucose, fructosamine and glycosylated haemoglobin in detecting diabetes and other glucose tolerance abnormalities compared to oral glucose tolerant test. Acta Diabetol. 2002;39:15-22.

23. Tanaka $Y$, Atsumi $Y$, Matsuoka K, Mokubo A, Asahina T, Hosokawa $\mathrm{K}$, et al. Usefulness of stable $\mathrm{HbA1c}$ for supportive marker to diagnose diabetes mellitus in Japanese subjects. Diabetes Res Clin Pract. 2001;53:41-5.

24. Ginde AA, Cagliero E, Nathan DM, Camargo CA. Value of risk stratification to increase the predictive validity of $\mathrm{HbA} 1 \mathrm{c}$ in screening for undiagnosed diabetes in the US population. J Gen Intern Med. 2008;23(9):1346-59.

25. Little RR, Roberts WL. A review of variant hemoglobins interfering with hemoglobin A1c measurement. J Diab Sci Tech. 2009;3(3):446-51.

26. National Diabetes Clearinghouse (NDIC). A service of the National Institute of Diabetes and Digestive and Kidney Diseases (NIDDK), National Institutes of Health (NIH). Sickle Cell Trait and Other Hemoglobinopathies and Diabetes: Important Information for Physicians. Available from: http://diabetes.niddk.nih.gov/dm/ pubs/hemovari-A1C/\#hemoglobinopathies. Accessed on: Apr 21, 2012.

27. Monnier L, Lapinski $\mathrm{H}$, Colette C. Contributions of fasting and postprandial plasma glucose increments to the overall diurnal hyperglycemia of type 2 diabetic patients: variation with increasing levels of HbA1c. Diabetes Care. 2003;26(3):881-3. 